Journal of Epidemiology and Community Health, 1984, 38, 7-11

\title{
Paternal occupation and Wilms' tumour in offspring
}

\author{
JOHN R WILKINS III AND THOMAS H SINKS JR
}

From the Department of Preventive Medicine, The Ohio State University, Columbus, Ohio 43210, USA

SUMMARY A case-control study was conducted to test the hypothesis that paternal occupation is a risk factor for Wilms' tumour in offspring. Occupations associated with exposure to lead $(\mathrm{Pb})$ and to hydrocarbons were examined by computing odds ratios, all of which were greater than unity but not by a statistically significant margin. When painters were considered separately, children whose fathers had been so employed were six times more likely to develop Wilms' tumour than children whose fathers had other occupations. Like the results for the $\mathrm{Pb}$ and hydrocarbon related occupations, the estimated relative risk associated with painters did not reach statistical significance. Although these data require cautious interpretation because of the relatively small number of subjects, the results reported here are not wholly consistent with the results of the one previous study of paternal occupation and Wilms' tumour in offspring.

Scientific interest in the potential health risks to children resulting from exposures of parents to carcinogens, mutagens, teratogens, or a combination of these, has intensified in recent years. ${ }^{1}$ With respect to childhood neoplasms resulting from parental exposures, numerous risk factors have been identified or suggested, one of which is paternal occupation. ${ }^{2-10}$

In one of the earliest investigations in this area Fabia and Thuy reported that children whose fathers were engaged in hydrocarbon related occupations were at a twofold higher risk of death from cancer than children whose fathers were not so employed. ${ }^{2}$ Since the publication of these results in 1974, other investigators have addressed the question of parental occupation and risk of cancer in offspring with mixed results. In one study Kantor et al matched cases of Wilms' tumour in the Connecticut tumour registry with children of the same age, race, and sex, ${ }^{5}$ and then classified the occupations of the fathers as stated on the birth certificates of the study subjects according to the method of Fabia and Thuy ${ }^{2}$ and Hakulinen $e t$ al. ${ }^{4}$ As reported, children who had fathers employed in hydrocarbon related occupations around the time of their birth were found to be 2.4 times more likely to develop Wilms' tumour than their counterparts whose fathers had not been so employed, whereas children whose fathers had jobs associated with lead $\mathrm{Pb}$ were 3.7 times more likely to develop Wilms' tumour. When paternal occupations defined as only $\mathrm{Pb}$-related-that is, without exposure to hydrocarbons-were considered the estimated relative risk of Wilms' tumour in offspring increased to $\mathbf{5 \cdot 0}$.
Because the findings of Kantor et al suggest a possible aetiological role for environmental factors in Wilms' tumour, ${ }^{5}$ the present study was undertaken. In general, our objective was to attempt a replication of the findings of Kantor et al by examining the occupations of fathers of Ohio born children with and without Wilms' tumour. While the possible effect of hydrocarbon related occupations was of interest, the reported association between so ubiquitous an environmental contaminant $\mathrm{as} \mathrm{Pb}$ and Wilms' tumour was of special interest.

\section{Materials and methods}

IDENTIFICATION OF CASES

Patients with Wilms' tumour were identified through the Columbus (Ohio) Children's Hospital Tumour Registry (CCHTR). Any patient with a diagnosis of Wilms' tumour whose records entered the CCHTR during the period 1 January 1950-31 October 1981 was considered a potential study subject. Patients identified by reviewing CCHTR records were included in case-control comparisons if and only if the diagnosis of Wilms' tumour was microscopically confirmed, the patient's mother was a resident of Ohio at the time of his/her birth, and the index child's Ohio birth certificate was found.

SELECTION OF CONTROLS

For each case included in the study, the birth certificates of two children were randomly selected from the Ohio birth certificate files to serve as controls. Children in the first control group were 
individually matched to the Wilms' tumour cases with respect to sex, race, and year of birth. Children in the second control group were individually matched to the case series with respect to sex, race, year of birth, and by mother's county of residence when the child was born.

To create a suitable sampling frame for the selection of the population based controls, the Ohio population from which the cases of Wilms' tumour originated-that is, the "population at risk" was specified. Because the CCHTR is not a statewide registry and because the Columbus Children's Hospital is not the only paediatric hospital in Ohio, specification of the population at risk was not straightforward. In estimating the cluster of Ohio counties representing the study population at risk, two factors were considered: the dynamic nature of in-patient service areas and the relative rarity of Wilms tumour.

The process of specifying the population at risk began by assigning the identified cases to specific Ohio counties according to their mother's county of residence, firstly, with respect to their mother's county of residence at the time of the case's birth, and then with respect to their mother's county of residence at the time of their diagnosis of Wilms' tumour. The maps of Ohio that resulted (maps that showed the number of patients with Wilms' tumour at the Columbus Children's Hospital plotted by county) were also constructed with respect to specific

Table 1 Data obtained from birth certificates of study subjects

\begin{tabular}{l}
\hline Variable \\
\hline Pertains to child: \\
Date of birth \\
Race \\
Sex \\
Weight at birth \\
Presence or absence of congenital anomaly \\
Pertains to mother of child: \\
Age \\
County of residence at time of birth \\
Level of education* \\
No of other children living \\
No of other children born alive, now dead \\
No of stillbirths \\
Date of last mensis* \\
Pertains to pregnancy and birth: \\
No of children in birth \\
Birth order (if multiple birth) \\
Complications \\
Duration of pregnancy $\dagger$ \\
Pertains to father of child: \\
Age \\
Level of education* \\
Occupation and industry $\dagger$ \\
\end{tabular}

\footnotetext{
- Appears on Ohio birth certificates after 1967.
}

†Appears on Ohio birth certificates before 1968. time periods, by both five year and ten year groupings over the 30 year study period. Although some between county migration of case mothers occurred between date of birth and date of diagnosis, it was negligible. With respect to possible temporal trends in the geographic inpatient service area of Columbus Children's Hospital, no shifts in the areal pattern were seen over the time periods examined. Expected numbers of cases were also calculated and compared on a county specific basis to the observed number of cases.

Counties with paediatric hospitals other than Franklin County (where Columbus Children's Hospital is located), counties adjacent to such counties, and counties where the expected number of cases greatly exceeded the observed number were not considered part of the geographical area representing the study population at risk. A set of 47 contiguous Ohio counties resulted. Regarding cancer in children, the size and location of the study area is consistent with what is currently known about patterns of medical referrals in Ohio with respect to both Columbus Children's Hospital and the other paediatric hospitals in the state.

COMPARISONS OF CASES AND CONTROLS

Several comparisons were made. Firstly, the birth certificate data available for study subjects (table 1) were compared. For variables in continuous form, differences between the case series and the two control groups were tested by a mixed model analysis of variance (ANOVA) with repeated measures. ${ }^{11} \mathrm{~A}$ posteriori pairwise differences among the three groups were examined by using the Newman-Keuls procedure. ${ }^{12}$ Frequency data were subjected to Chisquare tests when it was appropriate. Secondly, fathers of study subjects were classified with respect to their occupations (as stated on the birth certificates of their children) according to the method of Fabia and Thuy ${ }^{2}$, with slight modification. Using the definitions of exposure described in table 2, maximum likelihood estimates of relative risk for matched triplets were computed, as were approximate $95 \%$ confidence intervals. The methods of point and interval estimation are those described by Miettinen. ${ }^{13}$ When the number of triplets on which to base an estimate of the relative risk was exceedingly small, the exact test proposed by Miettinen was performed. ${ }^{14}$

\section{Results}

DESCRIPTION OF THE CASE SERIES

Over the course of the study period (1 January 1950-31 October 1981), the records of 145 patients with microscopically confirmed Wilms' tumour were 
Table 2 Occupations comprising each definition of exposure

\begin{tabular}{|c|c|c|c|}
\hline \multicolumn{2}{|l|}{ Hydrocarbon related occupations } & \multicolumn{2}{|l|}{ Lead related occupations } \\
\hline Narrow definition* & Broad definition* & \multirow[b]{2}{*}{ Exposure 3} & \multirow[b]{2}{*}{ Exposure 4} \\
\hline Exposure 1 & Exposure 2 & & \\
\hline Motor vehicle mechanic & Motor vehicle mechanic & Motor vehicle mechanic & Painter \\
\hline Service station attendant & Service station attendant & Service station attendant & \\
\hline Driver/heavy equipment operator & Driver/heavy equipment operator & Driver/heavy equipment operator & \\
\hline \multirow[t]{7}{*}{ Metal worker/machinist } & Metal worker/machinist & Metal worker/machinist & \\
\hline & Lumberman & Plumber & \\
\hline & Miner & Welder & \\
\hline & Painter & & \\
\hline & Printer & & \\
\hline & Leather worker & & \\
\hline & Factory worker, NEC† & & \\
\hline
\end{tabular}

* See references 6 and 10.

†Not elsewhere classified.

entered into the CCHTR. Of these, 105 satisfied the study inclusion criteria previously set forth.

\section{BIRTH CHARACTERISTICS OF CASES AND CONTROLS}

When cases and controls were compared with respect to the available birth related information (table 1), cases and controls were found to be remarkably similar, with one minor exception. The ANOVA detected a statistically significant difference among the three groups with respect to age of the fathers of study subjects: case fathers had an average age at the time of birth of their children of 27.8 years, while control fathers were, on average, 28.3 and 30.4 years of age. Since, on an overall basis, the birth related characteristics of cases and controls were so similar, multivariate analyses were not performed.

\section{PATERNAL OCCUPATION}

Because of changes in the Ohio birth certificate form (see footnotes, table 1), only 62 of the 105 matched triplets could be analysed with respect to paternal occupation. Thus 186 study subjects were classified according to their father's occupation at the time of their birth. As can be seen from the distributions of paternal occupation given in table 3, a greater proportion of fathers of cases had white collar jobs as compared with the fathers of either control group. Although this suggests the case series to be of a higher socioeconomic status than controls, it must be remembered that the results of the ANOVA indicated the level of education (for both parents) to be the same for all three groups. In general, the distributions are quite similar although the numbers are small.
Hydrocarbon related occupations-Tables 4 and 5 show the results of risk estimation for the hydrocarbon related occupations. Given are the distributions of the 62 matched triplets for which information on the father's occupation was available, the maximum likelihood point estimates of the odds ratio, and approximate $95 \%$ confidence limits. For both definitions of hydrocarbon related occupations, the odds ratios are greater than unity by about $40 \%$. As the confidence intervals indicate, however, the rise in risk is not statistically significant.

$P b$ related occupations-Table 6 gives the results for occupations defined as $\mathrm{Pb}$ related. In more than half of the 62 triplets examined, neither case nor either control were engaged in $\mathrm{Pb}$ related employment at the time of their child's birth. The deviation of the odds ratio of 1.25 from unity is not statistically significant, evidenced by the lower limit of the $95 \%$ confidence interval.

Painters-Table 7 gives the results of the matched triplets analysis for painters alone (exposure 4). Although the estimated odds ratio of 6.00 is quite high, it is not statistically significant, as the confidence interval indicates. Exact testing of the distribution of triplets yielded a two sided $p$ value of 0.22 .

\section{Discussion}

It was not possible in this study to show a statistically significant association between paternal occupations defined as hydrocarbon or $\mathrm{Pb}$ related and Wilms' tumour in offspring. These results must be considered, however, in the light of the relatively few subjects available for study. Since the statistical 
Table 3 Distribution of study subjects by father's occupation at time of birth

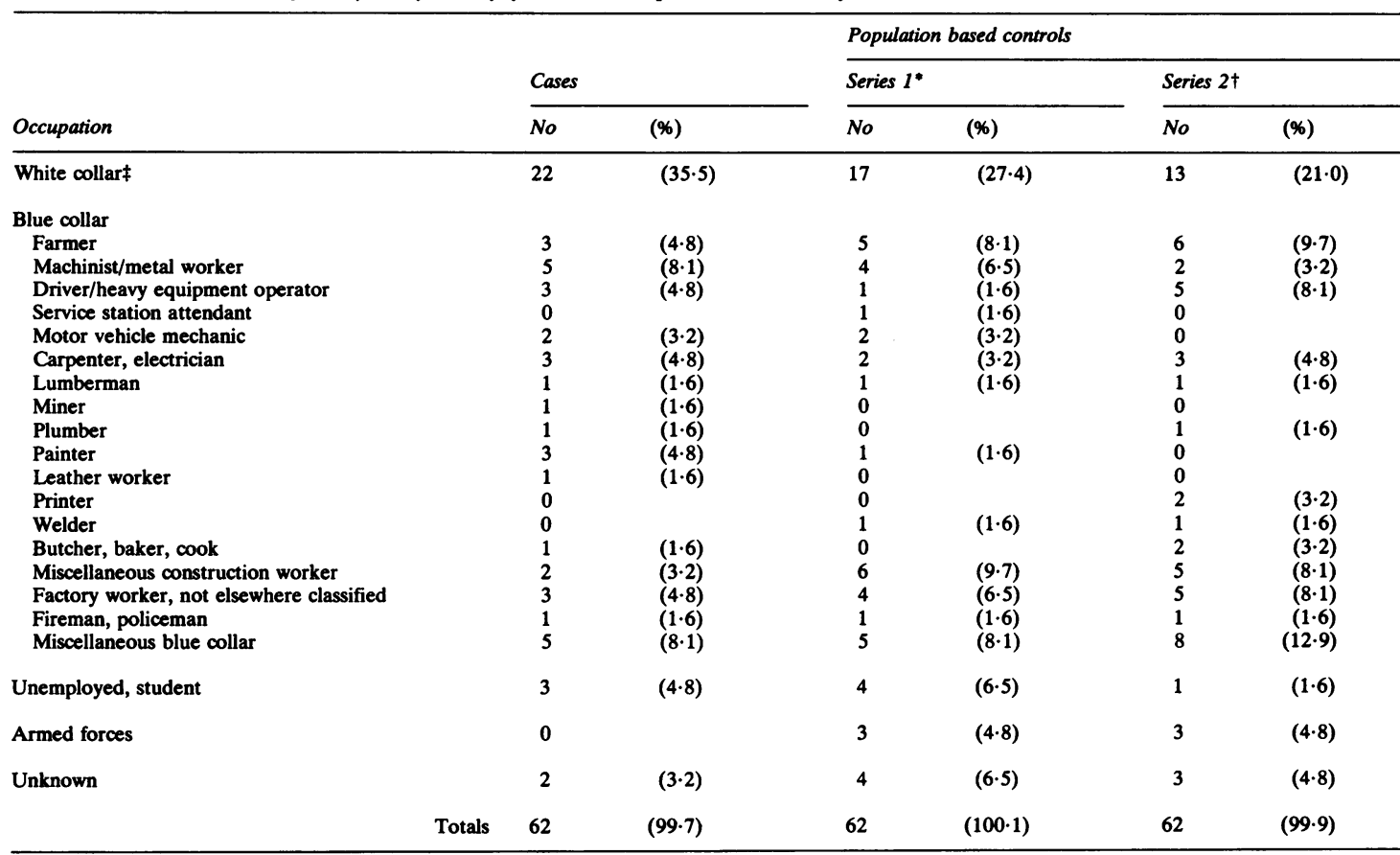

"Series 1 represents those controls individually matched to the case series by age, sex, and year of birth.

tSeries 2 represents those controls individually matched to the cases series by age, sex, year of birth, and mother's county of residence at time of birth.

¥White collar occupations are those considered either professional and technical, managerial and administrative, clerical, or involving sales and service.

Table 4 Distribution of matched triplets, odds ratio, and confidence limits for exposure $1^{*}$

\begin{tabular}{|c|c|c|c|c|c|c|}
\hline \multirow{2}{*}{\multicolumn{2}{|c|}{ Distribution of triplets }} & & & \multirow{4}{*}{ Odds ratio } & \multicolumn{2}{|c|}{$95 \%$ confidence limits } \\
\hline & & & & & \multirow[t]{3}{*}{ Lower } & \multirow[t]{3}{*}{ Upper } \\
\hline & & \multicolumn{2}{|l|}{ Cases } & & & \\
\hline & & \multicolumn{2}{|c|}{1 exposed 0 exposed } & & & \\
\hline Controls & $\begin{array}{l}2 \text { exposed } \\
1 \text { exposed } \\
0 \text { exposed } 1\end{array}$ & $\begin{array}{r}0 \\
0 \\
10\end{array}$ & $\begin{array}{r}2 \\
11 \\
39\end{array}$ & $1 \cdot 37$ & 0.59 & $3 \cdot 11$ \\
\hline
\end{tabular}

"Hydrocarbon related occupations (narrow definition).

Table 5 Distribution of matched triplets, odds ratio, and confidence limits for exposure $2^{*}$

\begin{tabular}{|c|c|c|c|c|c|c|}
\hline \multirow{2}{*}{\multicolumn{2}{|c|}{ Distribution of triplets }} & & & \multirow[b]{2}{*}{ Odds ratio } & \multicolumn{2}{|c|}{$95 \%$ confidence limits } \\
\hline & & & & & Lower & Upper \\
\hline & & \multicolumn{2}{|l|}{ Cases } & & & \\
\hline & & 1 exposed & 0 exposed & & & \\
\hline Controls & $\begin{array}{l}2 \text { exposed } \\
1 \text { exposed } \\
0 \text { exposed }\end{array}$ & $\begin{array}{r}0 \\
6 \\
13\end{array}$ & $\begin{array}{r}3 \\
17 \\
23\end{array}$ & 1.40 & 0.73 & 2.69 \\
\hline
\end{tabular}

"Hydrocarbon related occupations (broad definition).
Table 6 Distribution of matched triplets, odds ratio, and confidence limits for exposure $3^{*}$

\begin{tabular}{|c|c|c|c|c|c|c|}
\hline \multirow{2}{*}{\multicolumn{4}{|c|}{ Distribution of triplets }} & \multirow{4}{*}{ Odds ratio } & \multicolumn{2}{|c|}{$95 \%$ confidence limits } \\
\hline & & & & & \multirow[t]{3}{*}{ Lower } & \multirow[t]{3}{*}{ Upper } \\
\hline & & \multicolumn{2}{|l|}{ Cases } & & & \\
\hline & & 1 exposed & 0 exposed & & & \\
\hline Controls & $\begin{array}{l}2 \text { exposed } \\
1 \text { exposed } \\
0 \text { exposed }\end{array}$ & $\begin{array}{r}0 \\
0 \\
11\end{array}$ & $\begin{array}{r}3 \\
12 \\
36\end{array}$ & $1 \cdot 25$ & 0.56 & $2 \cdot 70$ \\
\hline
\end{tabular}

"Lead related occupations.

Table 7 Distribution of matched triplets, odds ratio, and confidence limits for exposure $4^{*}$

\begin{tabular}{|c|c|c|c|c|c|c|}
\hline \multirow{2}{*}{\multicolumn{2}{|c|}{ Distribution of triplets }} & & & \multirow{4}{*}{ Odds ratio } & \multicolumn{2}{|c|}{ 95\% confidence limits } \\
\hline & & & & & \multirow[t]{3}{*}{ Lower } & \multirow[t]{3}{*}{ Upper } \\
\hline & & Cases & & & & \\
\hline & & 1 exposed & 0 exposed & & & \\
\hline Controls & $\begin{array}{l}2 \text { exposed } \\
1 \text { exposed } \\
0 \text { exposed }\end{array}$ & $\begin{array}{l}0 \\
0 \\
3\end{array}$ & $\begin{array}{r}0 \\
1 \\
58\end{array}$ & 6.00 & 0.62 & $107 \cdot 32$ \\
\hline
\end{tabular}

*Painters. 
power of the study is therefore low, the non-positive findings reported here should not be regarded as strong or compelling evidence in favour of the null hypothesis - that is, that paternal occupation is not a risk factor for Wilms' tumour in offspring. Clearly, a study able to incorporate more subjects into an analysis would have greater statistical power, and thus (if such a study yielded non-positive results) would constitute a stronger argument in favour of the null. Since Wilms' tumour is very rare, sample size problems will probably always plague studies of this type. Accordingly, it would seem necessary to conduct a large multi-institutional study in order to confirm or disprove the findings of Kantor et al. ${ }^{5}$ Despite the question, however, about the power of the present study, the results reported here are nevertheless a contrast to the results of Kantor et al, at least with respect to the magnitude of the odds ratios: 1.4 here versus 2.4 in the study of Kantor et al for the hydrocarbon related occupations and 1.25 here versus 3.7 and 5.0 in their study for the $\mathrm{Pb}$ related occupations.

One important methodological problem relates to the treatment of the exposure variable of interest: paternal occupation. In this study, and in others, ${ }^{259}$ the fathers of study subjects were assigned to specific occupational categories before statistical analyses. Although such classifications could theoretically be based on the type of industry-for example, by using the Standard Industrial Classification Manual ${ }^{15}$-or on the type of occupational task-for example, by using the Dictionary of Occupational Titles ${ }^{16}$ - the scheme proposed by Fabia and Thuy ${ }^{2}$ has been used most frequently in this context. There does not seem to be any compelling reason to prefer one scheme over another. The problem is that the assumption of homogeneous exposures in each occupational category may or may not be valid. For example, the exposures of two "factory workers," without regard to the industry, are likely to be more dissimilar than similar. Furthermore, inferences regarding the specific chemical or physical agents of disease associated with each occupational group are best described as crude, particularly when detailed occupational histories are not available. One possible solution, particularly when the occupational or industrial affiliation or both is determined solely from routinely collected records, such as birth or death certificates, would be to use the occupation and exposure crosslinkage system described by Hoar $e t$ al. ${ }^{17}$ An overview of methodological problems often encountered in studies of parental occupation and cancer in offspring is given by Gold et al. ${ }^{10}$

Those epidemiological studies generally regarded as "first generation" cannot realistically be expected to provide the type of scientific evidence on which to make strong causal inferences. They can, however, in addition to their well established role as hypothesis generators be used to help improve the study design of 'second generation' studies. Assuredly, additional studies in this area are justified because the accumulated scientific evidence cannot currently be evaluated against established criteria for judging the nature of epidemiological associations. ${ }^{18} 19$

We thank the American Cancer Society (Ohio Division) for their support of this project. We also gratefully acknowledge Jill Williams for computer programming help, Patricia Price for manuscript preparation, and Dr W A Newton Jr and the staff of the Columbus Children's Hospital Tumour Registry.

\section{References}

${ }^{1}$ Haas JF, Schottenfeld D. Risks to the offspring from parental occupational exposures. JOM 1979; 21: 60613.

${ }^{2}$ Fabia J, Thuy TD. Occupation of father at time of birth of children dying of malignant diseases. Br J Prev Soc Med 1974; 28: 98-100.

${ }^{3} \mathrm{Kwa}$ S, Fine LJ. The association between parental occupation and childhood malignancy. JOM 1980; 22: 792-4.

'Hakulinen T, Salonen T, Teppo L. Cancer in the offspring of fathers in hydrocarbon-related occupations. $\mathrm{BrJ}$ Prev Soc Med 1976; 30: 138-40.

${ }^{5}$ Kantor AF, Curnen MGM, Meigs JW, Flannery JT. Occupations of fathers of patients with Wilms' tumour. $J$ Epidemiol Community Health 1979; 33: 253-6.

- Zack M, Cannon S, Loyd D, et al. Cancer in children of parents exposed to hydrocarbon related industries and occupations. Am J Epidemiol 1980; 111: 329-36.

${ }^{7}$ Hemminki K, Saloniemi I, Salonen T, Partanen T, Vaino H. Childhood cancer and parental occupation in Finland.J Epidemiol Community Health 1981; 35: 11-5.

${ }^{8}$ Peters JM, Preston-Martin S. Brain tumours in children and occupational exposure of parents. Science 1981; 213: 235-7.

${ }^{9}$ Sanders BM, White GC, Draper GJ. Occupations of fathers of children dying from neoplasm. $J$ Epidemiol Community Health 1981; 35: 245-50.

${ }^{10} \mathrm{Gold}$ EB, Diener MD, Szklo M. Parental occupations and cancer in children. JOM 1982; 24: 578-84.

${ }^{11}$ Dixon WJ, ed. BMDP statistical software. Berkeley: University of California Press, 1981.

${ }^{12}$ Winer BJ Statistical principles in experimental design. 2nd ed. New York: McGraw-Hill Book Company, 1971.

${ }^{13}$ Miettinen OS. Estimation of relative risk from individually matched series. Biometrics 1970; 26: 7585.

${ }^{14}$ Miettinen OS. Individual matching with multiple controls in the case of all-or-none responses. Biometrics 1969; 25: 339-55.

${ }^{15}$ Standard industrial classification manual. Washington DC;US Government Printing Office, 1972.

${ }^{16}$ Dictionary of occupational titles. 4th ed. Washington DC: US Government Printing Office, 1977.

${ }^{17}$ Hoar SK, Morrison AS, Cole P, Silverman DT. An occupation and exposure linkage system for the study of occupational carcinogenesis. JOM 1980; 22: 722-6.

${ }^{18}$ Lilienfield AM, Lilienfield DE. Foundations of epidemiology. 2nd ed. New York: Oxford University Press, 1980.

${ }^{19}$ Susser M. Causal thinking in the health sciences. New York: Oxford University Press, 1973. 